\title{
Guest Editorial: SiF'08 Special Issues 1 \& 2 Journal of Fire Technology
}

\author{
Venkatesh Kodur*, Michigan State University, East Lansing, USA
}

Structural fire safety is one of the key considerations in buildings since fire represents one of the most severe environmental hazards encountered by the built infrastructure. A number of recent white papers and reports, commissioned following the 9-11 disaster where fires played a severe destructive role, conclude that there is serious lack of data, tools, technologies and qualified personnel to facilitate structural fire safety design. This was mainly attributed to the fact that within the area of fire science, structural fire safety is the least developed. In addition, there are very few forums (conferences and workshops) devoted to structural fire engineering theme, for researchers and practitioners to exchanges their research results and learn the work of others.

To address the lack of forums in "Structures in Fire" (SiF) area, the idea of specialized workshop series was conceived in late 1990s and bore fruit in 2000 when the "First International SiF workshop" was organized in Copenhagen, Denmark. This was followed by "2nd, 3rd, and 4th International SiF workshops" that were held in New Zealand, Canada, and Portugal in 2002, 2004, and 2006, respectively. Over this period, the SiF movement and workshops have grown in size and stature, with increasing international awareness of its mission and vision. Taking note of this success, SiF members at the "4th International SiF workshop", endorsed the elevation of "SiF International Workshop" series to "International Conference on SiF" series. In addition, to recognize the growing importance of this forum, a steering committee was formed to oversee the SiF activities and conferences. Under this new frame work " 5 th International Conference on SiF" was organized by Nanyang Technological University, Singapore, in May 2008.

The "5th International Conference on SiF" (SiF'08) received a total of 106 abstracts. Based on the review of each abstract by at least three reviewers, selected from the scientific committee, the steering committee finalized 68 papers for publication in the conference proceedings. The submissions were of high quality and covered a broad range of topics with in structural fire engineering. The complete proceedings of the conference can be downloaded from http://www.ntu.edu.sg/cee/ sif-08/index.htm.

Prior to Singapore conference, Dr. John M. Watts, Jr., Editor of Journal of Fire Technology, contacted $\mathrm{SiF}$ steering committee on the possibility of producing special theme issues based on the papers presented at the SiF'08. Upon this request, $\mathrm{SiF}$ steering committee carried out a quick review of the papers and final-

\footnotetext{
* Correspondence should be addressed to: Venkatesh Kodur, E-mail: kodur@egr.msu.edu
} 
ized 36 papers for the special theme issues of Journal of Fire Technology. The authors of these selected papers were invited to submit the revised and enhanced version of their SiF'08 conference papers for possible publication in the special theme issues of the journal. The papers were reviewed as per the journal policy and the authors were again asked to address the comments of the reviewers. Based on the reviews and revisions, 15 papers were selected for publication in two theme issues of Journal of Fire Technology. The 15 papers are grouped in two issues: first issue dealing with papers relating to steel and composite structures, and the second issue dealing with concrete, timber, and lightweight framing construction.

The seven papers in Issue 1 present results from both experimental and numerical studies on various fire resistance topics related to steel and composite structures. The papers range from the topic of membrane action in composite floor slabs to the subject of effect of location of fire induced restraint in steel beams.

The second issue contains eight papers dealing with fire resistance of concrete, timber, and lightweight framing construction. The topics in this issue range from fire performance of bolted timber connections to fire induced spalling in high strength concrete beams.

The papers in these two special issues draw on the experience and special knowledge of academics and practitioners both in the academia and research organizations in Belgium, China, Czechoslovakia, France, Italy, New Zealand, Portugal, Sweden, Switzerland, United Kingdom, and the United States of America. The efforts of these authors and the critical assessment of the papers by reviewers, whose time and expertise are reflected in the quality of this publication, are gratefully acknowledged.

I am thankful to my Ph.D. student Mr. Monther Dwikat for his valuable support in organizing the reviews and also in finalizing the papers for this special issue of the Journal. Finally, I would like to acknowledge fellow SiF steering committee members (J. M. Franssen University of Liege, Belgium; A. Buchanan, University of Cantebury, New Zealand; and Paulo Vila Real, University of Aveiro, Portugal) and $\mathrm{SiF}^{\prime} 08$ organizing Committee Co-Chairs (K.H. Tan and C.H Tan, Nanyang Technological University, Singapore) for their efforts in organizing the "5th International Conference on SiF", without which the special theme issues would not have become a reality. 